\title{
Cutaneous metastases from cervical squamous cell carcinoma in a 55 year-old woman: a rarely reported manifestation
}

\author{
Whitney A. McCarthy ${ }^{1}$, Rodolfo Laucirica ${ }^{1,2}$ \\ 1. Department of Pathology \& Immunology, Baylor College of Medicine, Houston, Texas, USA. 2. Department of Pathology, \\ Ben Taub General Hospital-Harris Health System, Houston, Texas, USA.
}

Correspondence: Rodolfo Laucirica. Address: One Baylor Plaza MS: BCM315 Houston, Texas 77030, USA. E-mail: rodolfol@bcm.edu

Received: February 8, 2014

Accepted: March 23, 2014

Online Published: March 28, 2014

DOI : $10.5430 /$ crcp.v1n2p27

URL: http://dx.doi.org/10.5430/crcp.v1n2p27

\begin{abstract}
Squamous cell carcinoma of the cervix was once the most common gynecologic cancer in the world, accounting for significant morbidity and mortality. With the advent of routine Papanicolaou screening in the United States during the latter half of the twentieth century, cervical cancer now accounts for a much smaller proportion of cancer deaths. Despite the advances that have been made in screening and early detection, women of low socio-economic status and immigrants from other countries who may not have access to health care continue to present with high-stage disease. Manifestations of advanced disease include direct invasion of structures adjacent to the cervix and distant metastases to the lung, bone, and liver. In approximately 0.5-1 percent of cases, metastases to the skin and soft tissue occur, most commonly to the abdominal wall and vulva, followed less frequently by the perineum and extremities. This particular manifestation has come to be regarded as a sign of terminal disease, with most patients surviving 3-6 months despite chemotherapy. Clinically, this may not be a diagnosis that is anticipated by the pathologist examining the biopsy. We present the case of a 55 year-old woman with a history of untreated squamous cell carcinoma of the cervix who presented with rapidly spreading, painful erythematous papules of the vulva, lower anterior abdominal wall, and proximal lower extremities. This case highlights a rare presentation of metastatic squamous cell carcinoma of the cervix, and underscores the importance of obtaining adequate clinical history, investigating a wide range of diagnoses as part of the differential diagnosis, and distinguishing primary cutaneous squamous cell carcinoma from a metastasis.
\end{abstract}

\section{Key words}

Cutaneous, Metastases, Cervix, Squamous, Carcinoma

\section{Introduction}

In the United States, the prevalence of cervical cancer has decreased precipitously over the last five decades ${ }^{[1]}$, due in part to cervical screening by Papanicolaou smear and increased public awareness. In cases of cervical cancer that either progress or recur, common sites of metastasis include lymphatic spread, direct invasion into adjacent soft tissue or organs (e.g. parametria, bladder), and least commonly, hematogenous dissemination to distant sites such as liver, lung, and bone ${ }^{[2]}$. Metastases to the skin resulting from squamous cell carcinoma of the cervix have been rarely reported, with 
approximately fifty cases in the literature to date. This clinical scenario is even less common in literature originating from the United States, due to the lower overall incidence of cervical cancer ${ }^{[3-5]}$. Case reports have documented various sites of cutaneous metastases, including the face and neck ${ }^{[6]}$, scalp ${ }^{[7-9]}$, vulva ${ }^{[5,10-11]}$, upper and lower extremities ${ }^{[12-13]}$, umbilicus (Sister Mary Joseph nodule) ${ }^{[14]}$, trunk/abdominal wall ${ }^{[3-5,15]}$, and surgical incision/drain sites ${ }^{[16-17]}$. Prior authors have found that the occurrence of metastases to the skin generally implies terminal disease, with the average survival following diagnosis ranging from 3-6 months, even in cases where palliative chemo- and radiotherapy are administered ${ }^{\text {[15] }}$. We report a case of stage IV squamous cell carcinoma of the cervix metastatic to the skin in a 55 year-old woman with no prior treatment for her disease. Previous case reports have focused on the patient's clinical presentation and subsequent treatment, rather than the pathologists' approach to the diagnosis of this entity. This case report highlights the clinicopathologic features of cervical squamous cell carcinoma metastatic to the skin, and should aid the pathologist in the differential diagnosis of painful subcutaneous nodules in women with a history of cervical cancer. Finally, we briefly discuss the pathologist's role in distinguishing primary squamous cell carcinoma from metastases, including the use of potentially helpful immunohistochemical markers such as p16.

\section{Case presentation}

A 55 year-old woman presented to the emergency department in June 2013 with a history of squamous cell carcinoma of the cervix, diagnosed in October 2011. At the time, chemotherapy was recommended, but the patient was unable to undergo any treatment secondary to a lack of funding. The patient was then lost to follow-up for nineteen months. Later, she was admitted in April 2013 to another institution with vaginal bleeding and left lower extremity edema. The patient was found to have a left lower extremity deep venous thrombosis and bilateral hydroureteronephrosis with acute renal failure secondary to an obstructive process. At this time, the patient was determined to be a poor candidate for further therapy, and hospice care was recommended. One month later, the patient presented to our institution with a three-week history of numerous rapidly spreading painful papules located on the anterior abdominal wall, vulva, and bilateral proximal lower extremities (see Figure 1). Computed tomography imaging showed an area of fullness and enlargement in the region of the lower uterine segment and uterus, with mass effect on the bladder, along with an atrophic right kidney and left hydronephrosis. Due to the patient's elevated creatinine $(1.3 \mathrm{mg} / \mathrm{dl})$, intravenous contrast was not used, and thus, invasion of the bladder by the mass could not be definitively ascertained. Shave biopsies of the papules were obtained next, and showed invasive nests of mitotically-active squamoid cells with abundant eosinophilic cytoplasm and markedly pleomorphic nuclei, involving the papillary and reticular dermis, with a completely uninvolved overlying epidermis. Frequent abnormal mitotic figures were seen (see Figures 2-3). No lymphovascular space invasion was seen. In order to rule out synchronous primary cutaneous squamous cell carcinoma, a p16 immunohistochemical stain was performed, and was found to be diffusely and strongly positive in all tumor cells, both within the cytoplasm and nuclei; the overlying epidermis was negative (see Figure 4). This finding supported the final diagnosis of metastatic moderately differentiated squamous cell carcinoma, consistent with the patient's known cervical primary. The patient opted to return to her home country for treatment and was subsequently lost to follow-up. As a result, the patient's original cervical biopsy slides were not available; thus, morphologic correlation between those and the skin biopsies was not possible.

Figure 1. Erythematous papules on patient's lower abdomen, vulva, and upper thigh (photo A). Photo B shows a closer view of the confluent pink papules with ulceration. Photographs courtesy of Sarah Seyfer, M.D.
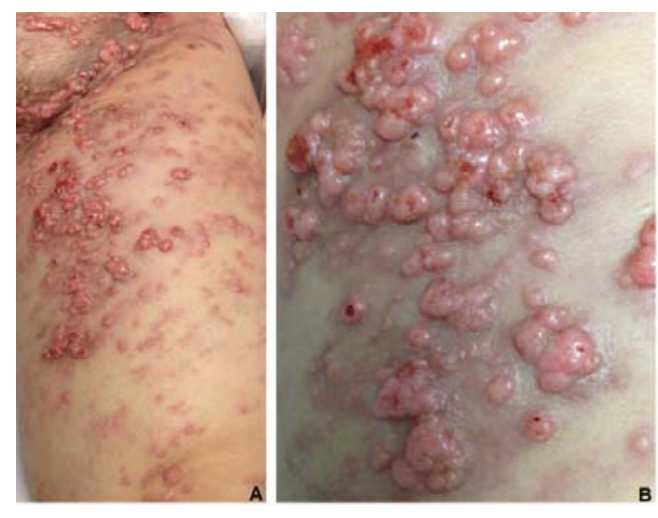

ISSN 2331-2726 E-ISSN 2331-2734 
Figure 2. Image of skin biopsy at $100 \times$ magnification (hematoxylin \& eosin stain). Irregular nests of squamous cells with markedly pleomorphic nuclei are present beneath the uninvolved epidermal surface.

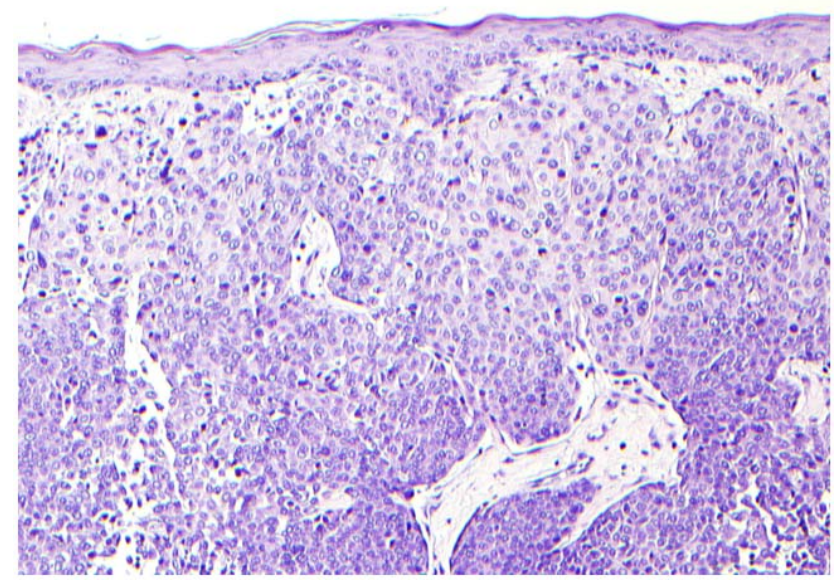

Figure 3. Image of skin biopsy at 200x magnification (hematoxylin \& eosin stain). At this power, the marked nuclear pleomorphism of the malignant squamous cells can be appreciated. Multiple abnormal mitotic figures are seen.

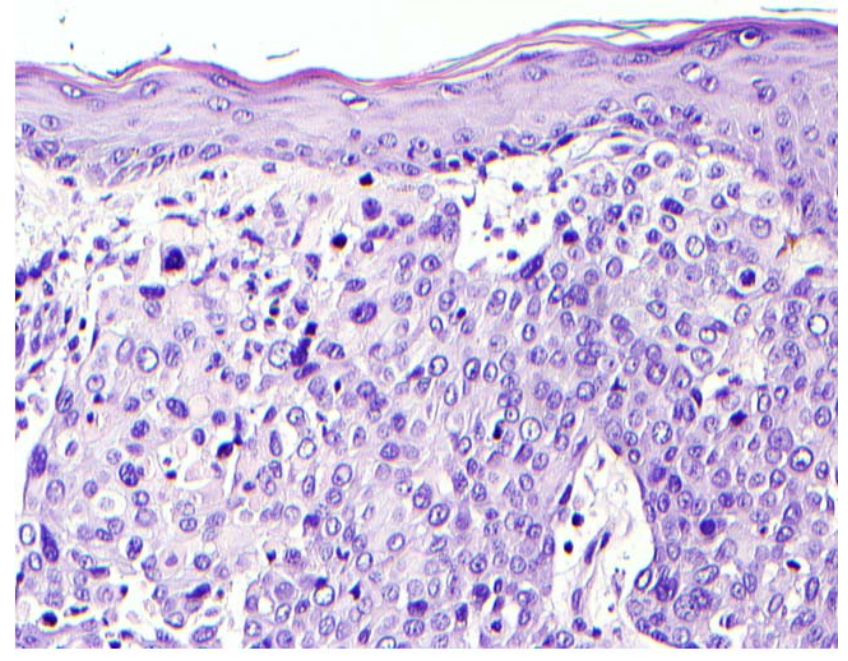

Figure 4. P16 immunohistochemistry performed on the skin biopsy shows diffuse, strong nuclear and cytoplasmic staining in the malignant squamous cells, while the squamous cells within the epidermis are completely negative.

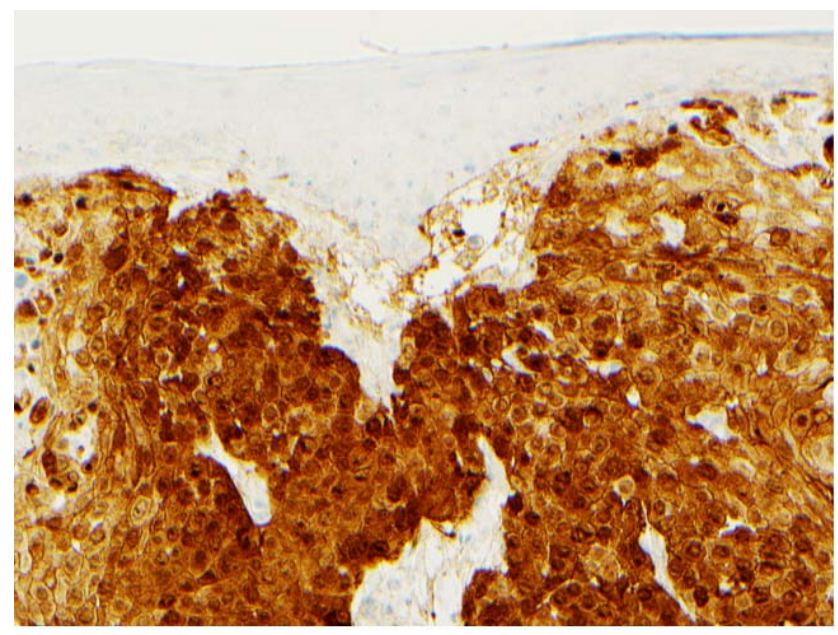

\section{Discussion}

The overall incidence and mortality from squamous cell carcinoma of the cervix has been on the decline for decades in the United States, mostly due to improved screening and detection of disease at earlier stages. However, patients of low socio-economic status and immigrants from other countries are vulnerable as a result of barriers to access for health 
care. Although the majority of advanced squamous cell carcinoma of the cervix will present as direct invasion of pelvic structures, or distant hematogenous metastases to the lung and bone, a rarely reported manifestation is cutaneous metastasis, which have been documented to occur in approximately $0.5-1$ percent of cases ${ }^{[18]}$.

In the case of this patient, nineteen months elapsed between diagnosis and her presentation with symptoms of advanced disease, including obstructive renal failure and metastases to the skin. In general, women with this late manifestation of advanced disease have a very poor prognosis, with survival documented between one week and five years after diagnosis ${ }^{[15]}$. Our patient was lost to follow-up, and ultimately, her length of survival is unknown. This case, however, is distinctive for several reasons. First, in prior reports of cutaneous metastases from cervical squamous cell carcinoma, the grossly visible nodules are usually single or a small cluster of multiple papules ${ }^{[3-17]}$. In our patient's case, the cutaneous metastases were innumerable and located diffusely over the anterior abdominal wall, vulva, perineum, and bilateral proximal lower extremities (see Figure 1). Secondly, the majority of reports documenting cutaneous cervical SCC metastases state that the appearance of cutaneous involvement occurred despite appropriate treatment, usually as a sign of recurrent disease ${ }^{[15]}$. Our patient had received no treatment, and this is likely why she presented with extensive, grossly apparent metastatic disease. This unfortunate scenario is illustrative of the natural history of untreated cervical cancer. This degree of extensive metastatic disease is vanishingly rare in literature originating from the United States, especially within the last ten to twenty years ${ }^{[3-5]}$.

From a diagnostic pathology standpoint, the nests of cells within the dermis were morphologically consistent with squamous cell carcinoma, comprised of cells with abundant eosinophilic cytoplasm and pleomorphic, hyperchromatic nuclei with abundant mitotic activity. However, the most significant question that faces the pathologist in this particular situation is whether or not this represents a second primary malignancy or a series of metastases from the known primary. Given the gross papular appearance of the nodules, basal cell carcinoma is an additional diagnostic consideration. However, the histopathology of the tumor is neither cytologically or architecturally consistent with this diagnosis, lacking cells with large, basophilic nuclei, a high nuclear to cytoplasmic ratio, and well-circumscribed nests of tumor cells with peripheral palisading and stromal retraction. Considering the patient's findings on imaging, additional differential diagnoses include metastatic urothelial carcinoma and other metastatic malignancies of gynecologic origin. Immunohistochemical markers such as cytokeratin 5/6, p40, and p63 may be used at the pathologists' discretion to confirm that the tumor is truly of squamous origin, and to rule out metastatic carcinomas from different sites ${ }^{[20,21]}$. In this case, given the patient's clinical history and presentation, a diagnosis of cutaneous metastases from the patient's primary cervical squamous cell carcinoma was favored. Immunohistochemical markers for P16 may be used in these situations to help elucidate whether or not this tumor represents metastatic disease. P16/INK4a (CDKN2A), a cyclin-dependent kinase that is dysregulated in high-risk human papillomavirus (HPV) infection ${ }^{[19]}$, accumulates within infected cells, and is thus amenable to detection by immunohistochemical methods and is often utilized as a surrogate marker for infection with high-risk HPV strains and/or detection of HPV-related malignancies ${ }^{[22]}$. Figure 4 demonstrates that in the biopsies from our patient, the nests of tumor within the dermis stained strongly and diffusely for $\mathrm{p} 16$, while the overlying epidermis was completely negative, ruling out the presence of a second primary squamous cell carcinoma. Of course, P16 is not entirely specific for HPV infection or for squamous cell carcinoma of the cervix, and positivity has been reported in a variety of tumors (both HPV- and non HPV-related), including cutaneous basal cell carcinomas, urothelial carcinoma, uterine serous carcinoma, and basal-like breast carcinoma ${ }^{[23-27]}$. However, immunohistochemical stains should never be interpreted without considering all other aspects of the case, such as the histopathology and clinical history. In this particular case, the morphologic and immunohistochemical results, coupled with the clinical history, supported a diagnosis of metastatic cervical squamous cell carcinoma.

In summary, cutaneous metastases from squamous cell carcinoma of the cervix are rarely reported, with approximately fifty cases within the world literature to date. This late manifestation has come to be widely regarded as a sign of disseminated, terminal disease ${ }^{[3]}$. The case presented in this report highlights the need for a complete clinical history to suspect metastatic disease and aid the pathologist in making the most accurate diagnosis for the patient. 


\section{Acknowledgement}

We would like to thank Sarah Seyfer, M.D. (Resident, Department of Dermatology, Baylor College of Medicine) for clinical photos related to the case.

\section{References}

[1] Crum CP, Cibas ES, Rose PG, Petersill WA. Cervical Squamous Neoplasia. In: Crum CP, Nucci MR, Lee KR, editors. Diagnostic Gynecologic and Obstetric Pathology. 2nd Edition. Philadelphia: Saunders Elsevier, 2011; p: 245-327

[2] Witkiewicz AK, Wright TC, Ferenczy A, Ronnett BM, Kurman RJ. Carcinoma and Other Tumors of the Cervix. In: Kurman RJ, Ellenson LH, Ronnett BM, editors. Blaustein's Pathology of the Female Genital Tract. 6th Edition. New York: Springer. 2011; P: 253-303.

[3] Malfetano JH. Skin metastasis from cervical cancer: a fatal event. Gynecol Oncol. 1986; 24: 177-182. PMID: 2940159. http://dx.doi.org/10.1016/0090-8258(86)90025-9

[4] Hayes AG, Berry AD. Cutaneous metastasis from squamous cell carcinoma of the cervix. J Am Acad Dermatol. 1992; 26(5): 846-850. PMID: 1613147. http://dx.doi.org/10.1016/0190-9622(92)70119-Z

[5] Lookingbill DP, Spangler N, Helm KF. Cutaneous metastases in patients with metastatic carcinoma: a retrospective study of 4020 patients. J Am Acad Dermatol. 1993; 29(2): 229-236. PMID: 8335743. http://dx.doi.org/10.1016/0190-9622(93)70173-Q

[6] Yang H, Lee M, Kuo T, Hong H. Cellulitis-like cutaneous metastasis of uterine cervical carcinoma. J Am Acad Dermatol. 2007; 56(2): S26-S28. PMID: 17097380. http://dx.doi.org/10.1016/j.jaad.2006.03.028

[7] Agarwal U, Dahiya P, Chauhan A, Sangwan K, Purwar P. Scalp metastasis in carcinoma of the uterine cervix-a rare entity. Gynecol Oncol. 2002; 87: 310-312. PMID: 12468331. http://dx.doi.org/10.1006/gyno.2002.6829

[8] Takagi H, Miura S, Matsunami K, Ikeda T, Imai A. Cervical cancer metastasis to the scalp: case report and literature review. Eur J Gynaecol Oncol. 2010; 31(2): 217-218. PMID: 20527246.

[9] Shimizu I, Hayashi S, Uehara M, Nakayama S. Cutaneous metastases to the scalp from carcinoma of the uterine cervix. Arch Dermatol. 1983; 119: 275-276. PMID: 6838231. http://dx.doi.org/10.1001/archderm.1983.01650280003001

[10] Deka D, Gupta N, Bahadur A, Dadhwal V, Mittal S. Umbilical surgical scar and vulval metastasis secondary to advanced cervical squamous cell carcinoma: a report of two cases. Arch Gynecol Obstet. 2010; 281: 761-764. PMID: 19789888. http://dx.doi.org/10.1007/s00404-009-1235-5

[11] Kim W, Park H, Kim H, Kim S, Ko H, Kim B, et al. Vulval metastasis from squamous cell carcinoma of the cervix clinically presenting as lymphangioma circumscriptum. Ann Dermatol. 2011; 23: 564-567. PMID: 22028576.

[12] Mehrotra S, Singh U, Gupta HP, Saxena P. Cutaneous metastasis from cervical carcinoma: an ominous prognostic sign. J Obstet Gynaecol. 2010; 30(1): 78-79. PMID: 20121522. http://dx.doi.org/10.3109/01443610903383374

[13] Elamurugan TP, Agrawal A, Dinesh R, Aravind R, Naskar D, Kate V, et al. Palmar cutaneous metastasis from carcinoma cervix. Indian J Dermatol Venereol Leprol. 2011; 77: 252-254. PMID: 21393976. http://dx.doi.org/10.4103/0378-6323.77486

[14] Behtash N, Mehrdad N, Shamshirsaz A, Hashemi R, Hashemi FA. Umbilical metastasis in cervical cancer. Arch Gynecol Obstet. 2008; 278: 489-491. PMID: 18379810. http://dx.doi.org/10.1007/s00404-008-0617-4

[15] Agrawal A, Yau A, Magliocco A, Chu P. Cutaneous metastatic disease in cervical cancer: a case report. J Obstet Gynaecol Can. 2009; 32(5): 467-472. PMID: 20500956.

[16] Behtash N, Ghaemmaghami F, Yarandi F, Ardalan FA, Khanafshar N. Cutaneous metastasis from carcinoma of the cervix at the drain site. Gynecol Oncol. 2002; 85: 209-211. PMID: 11925148. http://dx.doi.org/10.1006/gyno.2001.6559

[17] Srivastava K, Singh S, Srivastava M, Srivastava AN. Incisional skin metastasis of a squamous cell cervical carcinoma 3.5 years after radical treatment—a case report. Int J Gynecol Cancer. 2005; 15: 1183-1186. PMID: 16343209. http://dx.doi.org/10.1111/j.1525-1438.2005.00173.x

[18] Brady LW, O’Neil EA, Farber SH. Unusual sites of metastases. Semin Oncol. 1977; 4: 59-64. PMID: 841351.

[19] Neoplasia. In: Kumar V, Abbas AK, Fausto N, Aster JC. Robbins and Cotran Pathologic Basis of Disease. 8th Edition. Philadelphia: Saunders Elsevier. 2011; p: 259-330

[20] Wick, MR, Swanson, PE, Patterson, JW. Immunohistology of Skin Tumors. In: Dabbs, D., editor. Diagnostic Immunohistochemistry: Theranostic and Genomic Applications, Third Edition. Philadelphia: Elsevier; 2010.

[21] Tacha, D, Bremer, R, Haas, T, Qi, W. An immunohistochemical analysis of a newly developed, mouse monoclonal p40 (BC28) in lung, bladder, skin, breast, prostate, and head and neck cancers. Arch Pathol Lab Med. 2014; Early Online Release. PMID: 24528495. http://dx.doi.org/10.5858/arpa.2013-0342-OA 
[22] Lakshmi, S, Rema, P, Somanathan, T. p16ink4a is a surrogate marker for high-risk and malignant cervical lesions in the presence of human papillomavirus. Pathobiology. 2009; 76: 141-148. PMID: 19468254. http://dx.doi.org/10.1159/000209392

[23] Subhawong, AP, Subhawong, T, Nassar, H, Kouprina, N, Begum, S, Vang, R, et al. Most basal-like breast carcinomas demonstrate the same Rb-/p16+ immunophenotype as the HPV-related poorly differentiated squamous cell carcinomas which they resemble morphologically. Am J Surg Pathol. 2009; 33(2): 163-175. PMID: 18936692. http://dx.doi.org/10.1097/PAS.0b013e31817f9790

[24] Chiesa-Vottero, AG, Malpica, A, Deavers, MT, Broaddus, R, Nuovo, GJ, Silva, EG. Immunohistochemical overexpression of p16 and p53 in uterine serous carcinoma and ovarian high-grade serous carcinoma. Int J Gynecol Pathol. 2007; 26(3): 328-333. PMID: 17581420. http://dx.doi.org/10.1097/01.pgp.0000235065.31301.3e

[25] Vang, R, Gown, AM, Farinola, M, Barry, TS, Wheeler, DT, Yemelyanova, A, et al. p16 expression in primary ovarian mucinous and endometrioid tumors and metastatic adenocarcinomas in the ovary: utility for identification of metastatic HPV-related endocervical adenocarcinoma. Am J Surg Path. 2007; 31(5): 653-663. PMID: 17460447.

[26] Paolini, F, Carbone, A, Benevolo, M, Silipo, V, Rollo, F, Covello, R, et al. Human papillomaviruses, p16ink4a, and Akt expression in basal cell carcinoma. J Exp Clin Cancer Res. 2011; 30:108. PMID: 22082146. http: dx.doi.org/10.1186/1756-9966-30-108

[27] Yin, M, Bastacky, S, Parwani, AV, McHale, T, Dhir, R. p16ink4 immunoreactivity is a reliable marker for urothelial carcinoma in situ. Hum Pathol. 2008; 39(4): 527-535. PMID: 18234280. http://dx.doi.org/10.1016/j.humpath.2007.08.005 